(1)

CrossMark

\title{
Noninvasive ventilation for acute respiratory failure: the next step is to know when to stop
}

\author{
Óscar Peñuelas ${ }^{1,2}$ and Andrés Esteban ${ }^{1,2}$ \\ Affiliations: ${ }^{1}$ Intensive Care Unit, Hospital Universitario de Getafe, Madrid, Spain. ${ }^{2}$ CIBER de Enfermedades \\ Respiratorias, CIBERES, Spain. \\ Correspondence: Andrés Esteban, Hospital Universitario de Getafe, Madrid, Intensive Care Unit, Hospital \\ Universitario de Getafe, Madrid, Carretera de Toledo km 12.5, 28905, Getafe, Madrid, Spain. \\ E-mail: aestebanducigetafe.com
}

@ERSpublications

A definitive decision to interrupt an attempt at noninvasive ventilation in critical patients presents a clinical challenge that modifies the outcome http://ow.ly/Xrxo30l2D8E

Cite this article as: Peñuelas Ó, Esteban A. Noninvasive ventilation for acute respiratory failure: the next step is to know when to stop. Eur Respir J 2018; 52: 1801185 [https://doi.org/10.1183/13993003.01185-2018].

Noninvasive ventilation (NIV) is commonly used in the acute care setting for critically ill patients with acute respiratory failure (ARF), and has gained much academic, research and clinical interest based on the marked decrease in clinical outcomes (intubation and mortality) compared with usual care in the intensive care unit (ICU) setting.

As a result of intense physiological research and well conducted clinical trials [1-6], NIV combined with medical treatment is now standard care for specific conditions. As such, the European Respiratory Society and American Thoracic Society have published new recommendations for the clinical application of NIV based on the most current literature [7]. Particularly, the application of NIV was strongly recommended for two types of patients; for those with ARF leading to acute or acute-on-chronic respiratory acidosis due to exacerbation of chronic obstructive pulmonary disease, and for patients with ARF due to cardiogenic pulmonary oedema. However, given the uncertainty of evidence, the consensus was unable to offer a recommendation on the use of NIV for de novo ARF, including asthma, acute respiratory distress syndrome and pneumonia [7].

However, the application of NIV has increased in recent years according to the latest observational studies, both for recommended pathologies and others less recommended. Indeed, EsTEBAN et al. [8] reported that the use of NIV as the first choice of ventilatory support in ICU admissions has increased significantly over a 12 -year period: $5 \%$ in $1998,10 \%$ in 2004 , and $14 \%$ in $2010(\mathrm{p}<0.001)$.

Demoule et al. [9] performed an observational study and found that, although NIV may avoid the need for invasive mechanical ventilation in critically ill patients, a trial of failed NIV is associated with worse clinical outcomes compared with the use of invasive mechanical ventilation without a previous NIV trial. The failure of NIV, understood as the need for endotracheal intubation, is around $30 \%$ and it is especially important to note that the mortality of patients with successful NIV (without the need for intubation) is around $10 \%$, while in the group that fails an NIV trial, the overall mortality is significantly higher, reaching $47 \%$. In a recent observational study, SCHNELl et al. [10] found that NIV failure was an independent risk factor for mortality (adjusted hazard ratio 4.2, 95\% CI 2.8-6.2; p<0.0001) in patients with ARF. 
In this issue of the European Respiratory Journal, DANGERS et al. [11] have interestingly reported that the identification of moderate to severe dyspnoea in 426 patients with ARF who receive NIV was associated with unfavourable clinical outcomes. Dyspnoea after the first NIV session, but not dyspnoea on ICU admission or the absolute variation of dyspnoea, was independently associated with NIV failure (adjusted odds ratio (aOR) 2.41, 95\% CI 1.49-3.91; $\mathrm{p}<0.001$ ), and also with hospital mortality (aOR 2.11, 95\% CI 1.21-3.69; $\mathrm{p}=0.009)$. These results suggested that improvement of moderate to severe dyspnoea after the first NIV session designed to treat ARF may constitute a useful marker of the response to NIV at bedside. Therefore, these findings are relevant but some other clinical issues deserve to be highlighted.

The higher risk of failure of NIV and mortality might be related to different variables. This association may reflect either a causal effect (with NIV failure contributing to cause death) or a confounding effect (with NIV failure being a marker for more severe underlying disease). In addition, the results obtained in this study may allow the identification of dyspnoea as a marker of severity of disease and, therefore, a lack of improvement of dyspnoea as predictor for failure of NIV and mortality.

The tolerance of NIV is another relevant aspect for the success of NIV, and dyspnoea may lead the patient to refuse ongoing NIV, prompting its discontinuation. Muriel et al. [12] analysed the employment of sedatives and analgesic drugs in order to prevent NIV intolerance in 842 adult, critically ill patients with ARF who received NIV as first-line therapy in a prospective observational study, and found that the combined use of sedatives and analgesic drugs was independently associated with poor clinical outcomes, both failure of NIV (OR 5.7, 95\% CI 1.8-18.4; p=0.004) and 28-day mortality after adjustment for confounders (OR 4.6, 95\% CI 2.1-9.9; $\mathrm{p}<0.001$ ).

Another aspect associated with the failure of NIV may be related to the grade of severity of the illness leading to the failure of NIV. CARTEAUX et al. [13] analysed first-line ventilatory support in de novo ARF in 62 patients, to determine whether a high tidal volume (VT) during NIV could be deleterious and associated with NIV failure (defined as the need for intubation). The pressure support level was targeted to reach an expired $V \mathrm{~T}$ of $6-8 \mathrm{~mL}$ per $\mathrm{kg}$ of predicted body weight (PBW), and positive end-expiratory pressure was kept below $10 \mathrm{cmH}_{2} \mathrm{O}$. The mean expiratory $V \mathrm{~T}$ was $9.8 \mathrm{~mL}$ per $\mathrm{kg}$ of $\mathrm{PBW}$, and most patients $(77 \%)$ had a mean $V$ T above $8 \mathrm{~mL}$ per $\mathrm{kg}$ of PBW. NIV failed in 52\% of patients, and mortality in this group once again was very high (64\%). A multivariate analysis identified Simplified Acute Physiology Score II (SAPSII) at admission and mean expiratory $V \mathrm{~T}$ as independent risk factors for NIV failure. Particularly, in patients with moderate-to-severe hypoxaemia, a mean expiratory $V \mathrm{~T}$ more than $9.5 \mathrm{~mL}$ per $\mathrm{kg}$ PBW recorded over the first four cumulative hours of NIV accurately predicted NIV failure.

Finally, recent evidence also raises concern about potential deleterious effects of NIV mediated by a delay in invasive mechanical ventilation. This may have important clinical implications because one plausible explanation is that inadequate or prolonged use of NIV delays endotracheal intubation in critically ill patients, and thereby jeopardising the patient's odds of clinical recovery. In 221 patients randomly assigned to NIV or standard medical therapy, EsTEBAN et al. [14] evaluated the efficacy of NIV for preventing the need for reintubation or reducing mortality in unselected patients who had ARF after extubation, and found that the median time from respiratory failure to reintubation was longer in those patients that died in the NIV group ( $12 \mathrm{~h}$ versus $2.5 \mathrm{~h} ; \mathrm{p}=0.02)$ than in those who died in the standard therapy group. This result has been also observed by BELLAN et al. [15] in a large observational study including 436 immunocompetent patients with de novo ARF, and showed that a decline in ratio of arterial oxygen tension to inspired oxygen fraction between day 1 and 2 of NIV was independently associated with an increased mortality in NIV patients.

All these parameters could be used to stratify patients at the bedside when deciding to treat patients with NIV or when deciding to terminate NIV and proceed to invasive mechanical ventilation.

Currently, there are two unresolved clinical challenges: the first is to identify a subgroup of patients that are at higher risk of failure of NIV, and so a closer monitoring is mandatory. In this sense, DANGERs et al. [11] have contributed with their findings related to grading the severity of dyspnoea during the trial of NIV as a variable in NIV failure. The second challenge is in using a clinical approach to determine when the attempt at NIV is considered to have failed, and therefore must stop and treatment continue with invasive mechanical ventilation.

Taking into account these considerations, criteria predicting NIV failure, i.e. dyspnoea, would help clinicians choose between NIV and endotracheal intubation as first-line treatment, and the delay in the making-decision process is the cornerstone for the management of NIV in critically ill patients with ARF. Consequently, selecting patients for NIV and closely monitoring the response to NIV in order to rapidly identify the failure of NIV, stop NIV and proceed to invasive mechanical ventilation are crucial. 
Conflict of interest: None declared.

\section{References}

1 Brochard L, Mancebo J, Wysocki M, et al. Noninvasive ventilation for acute exacerbations of chronic obstructive pulmonary disease. N Engl J Med 1995; 333: 817-822.

2 Masip J, Betbesé AJ, Páez J, et al. Non-invasive pressure support ventilation versus conventional oxygen therapy in acute cardiogenic pulmonary oedema: a randomised trial. Lancet 2000; 356: 2126-2132.

3 Antonelli M, Conti G, Rocco M, et al. A comparison of noninvasive positive-pressure ventilation and conventional mechanical ventilation in patients with acute respiratory failure. N Engl J Med 1998; 339: 429-435.

4 Delclaux C, L'Her E, Alberti C, et al. Treatment of acute hypoxemic nonhypercapnic respiratory insufficiency with continuous positive airway pressure delivered by a face mask: a randomized controlled trial. JAMA 2000; 284 : 2352-2360.

5 Jaber S, Lescot T, Futier E, et al. Effect of noninvasive ventilation on tracheal reintubation among patients with hypoxemic respiratory failure following abdominal surgery: a randomized clinical trial. JAMA 2016; 315: 1345-1353.

6 Frat JP, Ragot S, Girault C, et al. Effect of non-invasive oxygenation strategies in immunocompromised patients with severe acute respiratory failure: a post hoc analysis of a randomised trial. Lancet Respir Med 2016; 4: 646-652.

7 Rochwerg B, Brochard L, Elliott MW, et al. Official ERS/ATS clinical practice guidelines: noninvasive ventilation for acute respiratory failure. Eur Respir J 2017; 50: 1602426.

8 Esteban A, Frutos-Vivar F, Muriel A, et al. Evolution of mortality over time in patients receiving mechanical ventilation. Am J Respir Crit Care Med 2013; 188: 220-230.

9 Demoule A, Girou E, Richard JC, et al. Benefits and risks of success or failure of noninvasive ventilation. Intensive Care Med 2006; 32: 1756-1765.

10 Schnell D, Timsit JF, Darmon M, et al. Noninvasive mechanical ventilation in acute respiratory failure: trends in use and outcomes. Intensive Care Med 2014; 40: 582-591.

11 Dangers L, Montlahuc C, Kouatchet A, et al. Dyspnoea in patients receiving noninvasive ventilation for acute respiratory failure: prevalence, risk factors and prognostic impact. Eur Respir J 2018; 52: 1702637.

12 Muriel A, Peñuelas O, Frutos-Vivar F, et al. Impact of sedation and analgesia during noninvasive positive pressure ventilation on outcome: a marginal structural model causal analysis. Intensive Care Med 2015; 41: 1586-1600.

13 Carteaux G, Millán-Guilarte T, De Prost N, et al. Failure of noninvasive ventilation for de novo acute hypoxemic respiratory failure: role of tidal volume. Crit Care Med 2016; 44: 282-290.

14 Esteban A, Frutos-Vivar F, Ferguson ND, et al. Noninvasive positive-pressure ventilation for respiratory failure after extubation. N Engl J Med 2004; 350: 2452-2460.

15 Bellani G, Laffey JG, Pham T, et al. Noninvasive ventilation of patients with acute respiratory distress syndrome. Insights from the LUNG SAFE Study. Am J Respir Crit Care Med 2017; 195: 67-77. 